\title{
Olivine Flotation and Settling Experiments on the Join $\mathrm{Mg}_{2} \mathrm{SiO}_{4}-\mathrm{Fe}_{2} \mathrm{SiO}_{4}$
}

\author{
Claude T. Herzberg ${ }^{1}$, Michael B. Baker ${ }^{2}$, and Richard F. Wendlandt ${ }^{3}$ \\ 1 Department of Geological Sciences, Rutgers University, New Brunswick, New Jersey 08903, USA \\ 2 Department of Earth and Planetary Science, Massachusetts Institute of Technology, Cambridge, Massachusetts 02139, USA \\ 3 Lunar and Planetary Institute, 3303 NASA Road 1, Houston, Texas 77058, USA
}

\begin{abstract}
Some unusual density relations between olivine and coexisting liquid in the system fosterite-fayalite are reported. At 1 atmosphere pressure olivine floats on its coexisting liquid for intermediate compositions on this binary because of extreme partitioning of $\mathrm{Fe}$ into the melt phase. At 20 kilobars the usual behavior of olivine settling occurs because the partitioning of $\mathrm{Fe}$ in the melt is reduced, aided possibly by the dissolution of $\mathrm{CO}_{2}$ in the melt from use of a graphite container. Olivine flotation and settling are rapid in a time period of only a few hours because viscosities are a little greater than that of paraffin oil at room temperature. Some adcumulate textures with good triple junction grain boundaries are developed. General observations of differentiated magmatic systems on a number of scales and experimental data indicate that the mechanisms by which magmas can differentiate vary considerably in the ultramafic to tholeiitic compositional range.
\end{abstract}

\section{Introduction}

In a paper by McBirney and Noyes (1979) on the differentiation of the Skaergaard intrusion, a strong and convincing case was made for in situ crystallization (eg., Jackson 1961) based on non-Newtonian properties of the magma as well as field observations such as (i) layering on the roof, walls, and floor (ii) the densities of plagioclase and mafic minerals are less than and greater than that of magma respectively, yet these minerals are distributed throughout the intrusion and (iii) numerous textures can be attributed to crystal growth in situ including graded and rhythmic layering. Indeed, numerous petrologists have noted that in the best documented layered intrusions there are no clear accumulations of floated plagioclase near the roof contact (eg., McBirney and Noyes 1979; Irvine 1980); where anorthosites do occur they can be found in relatively low stratigraphic horizons such as those in the Bushveld and Stillwater intrusions (Hall 1932; McCallum et al. 1980).

Although some authors totally reject the importance of crystal settling in convecting and nonconvecting media (Rice 1981), an important alternative has crystal growth on vertical walls of convecting magma chambers, flotation or settling of the residual liquid along the upwelling or downwelling convection cell limb depending on its density, and ultimately the development of a magma chamber with

Reprint requests to: C.T. Herzberg vertical composition gradients and horizontal double-diffusive layers (Turner 1980; Turner and Gustafson 1981). The end product of this model may be similar to simple phase settling and flotation; however, it may be a much more efficient way of affecting phase separation particularly in high viscosity magmas.

There are actually many examples of crystal settling, including filter pressing variants, and these have received a considerable amount of attention (eg., Daly 1914; Bowen 1919; Irvine 1980). However, the scale where this is best developed is characteristically larger than those which are readily accessible to direct observation. Although poorly understood, it is generally acknowledged that the earth has been differentiated by processes involving silicate liquids (eg., Safronov 1978). On another planetary scale, the fact that plagioclase can float (Bottinga and Weill 1970; Campbell et al. 1978) has been used extensively in models of the differentiation of the earth's moon which must explain a lunar stratigraphy consisting of an uppermost layer or unit of anorthosite (Wood et al. 1970; Longhi and Boudreau 1979; Herzberg and Baker 1980).

Although apparently self evident, the very existence of volcanoes is proof that magmas can separate from their source regions at depth in the earth and ascent because of buoyancy forces. Indeed, this occurs even where the proportion of liquid to solid is small (ie., low degrees of partial melting; see for example O'Hara 1968 and Stolper et al. 1981) and the crystal mush assumes the properties of viscoelastic solids; these conditions are considered necessary for the prevention of solid-liquid phase separation and segregation in a gravity field for many layered intrusions of a tholeiitic composition (McBirney and Noyes 1979). Clearly, strong rheological changes can develop from the point of magma segregation in the mantle to eventual crystallization in the crust, and this must be due in part to changes in the composition of the melt phase (eg., O'Hara 1968), although deviatoric stresses in the mantle may help to promote melt segregation (Spera 1980). Gravity-induced phase separation is likely to be a much more important process in picritic or ultramafic magmas generated in the mantle than their evolved tholeiitic counterparts in the crust. This can also explain rather well why we perceive many examples of in situ crystallization such as granite plutons, the Skaergaard intrusion, and many basic sills in the earth's crust, but few striking examples of crystal settling. Many picritic and ultramafic magmas do not intrude into or extrude on the earth's crust where crystal settling 
can operate for eventual inspection because the densities of these magmas are too high (Huppert and Sparks 1980; Stolper and Walker 1980); they probably remain in the mantle or pond below a low density boundary layer such as basaltic magma chambers along oceanic ridges and the base of the crust (ie., noteworthy exceptions are the unusual Archean komatiite flows with large volumes of basal olivine cumulates; Arndt et al. 1977). Our scale of observation can thus determine the importance we place on mechanisms of differentiation.

Although the rheological properties of magmas need to be understood quantitatively (Spera 1980), this paper will only attempt to illustrate conceptually the importance of viscosity on phase separation in ultramafic compositions. This is shown by some unusual density relations between olivine and its coexisting liquid in the system forsteritefayalite at low and high pressures and the extraordinarily high rate at which olivine settles and floats in these experiments.

\section{Experimental Observations}

Figure 1 is a reproduction of the forsterite-fayalite solidusliquidus loop determined experimentally by Bowen and Schairer (1935). The historical integrity of this diagram has been maintained although the reader should be reminded that in fact fayalite, and presumably other compositions on this join, melt incongruently to metallic $\mathrm{Fe}+$ liquid.

The densities of coexisting olivine and liquid pairs along the loop were calculated, and the results are given in Fig. 2. The densities of the solid olivine compositions were determined from their values at $25^{\circ} \mathrm{C}$ adjusted for the effects of thermal expansion using thermal expansivities of 3.2 to $3.8 \times 10^{-5 \circ} \mathrm{C}^{-1}$ [Fisher and Medaris 1969; Smyth 1975; Hazen $\left.1976 ; \alpha=1 / \mathrm{V}(\partial V / \partial T)_{p}\right]$. The densities of the liquid compositions were determined from the partial molar volumes and thermal expansivities of $\mathrm{MgO}$ and $\mathrm{SiO}_{2}$ reported by Bottinga et al. (1982) and for $\mathrm{FeO}$ those given by Nelson and Carmichael (1979).

If the errors in these silicate liquid compositions are less than about $\pm 1 \%$ (Nelson and Carmichael 1979), olivine crystals should have lower densities than their coexisting liquid compositions along most intermediate compositions along this join at 1 atmosphere pressure. The possibility that olivine might float was tested experimentally and verified.

One experiment was run on the bulk composition $\left(\mathrm{Mg}_{0.3} \mathrm{Fe}_{0.7}\right)_{2} \mathrm{SiO}_{4}$ where the density relations shown in Fig. 2 indicate that olivine is less dense than its coexisting liquid at $1,425^{\circ} \mathrm{C}$ and 1 atmosphere pressure. The experimental methods used were very similar to those adopted by Bowen and Schairer (1935) but with a number of exceptuons. The amount of sample used was large (ie., $200 \mathrm{mg}$ ), and the inner diameter of the spec pure Fe container was similarly large (ie., $4 \mathrm{~mm}$ ). This was required in order to minimize capillary action and concomitant draining of the capsule of its contents during the course of the experiment. The sample was run at $1,425^{\circ} \mathrm{C}$ for $2.5 \mathrm{~h}$ with the oxygen fugacity crudely controlled by an argon atmosphere.

The results of this experiment is shown in Fig. 3. Cumulate olivine crystals had floated to the top as anticipated by the calculated densities, and the extent of the solid-liquid phase separation was strong in only $2.5 \mathrm{~h}$. Using the lever rule and Fig. 1, the bulk olivine to liquid proportion is

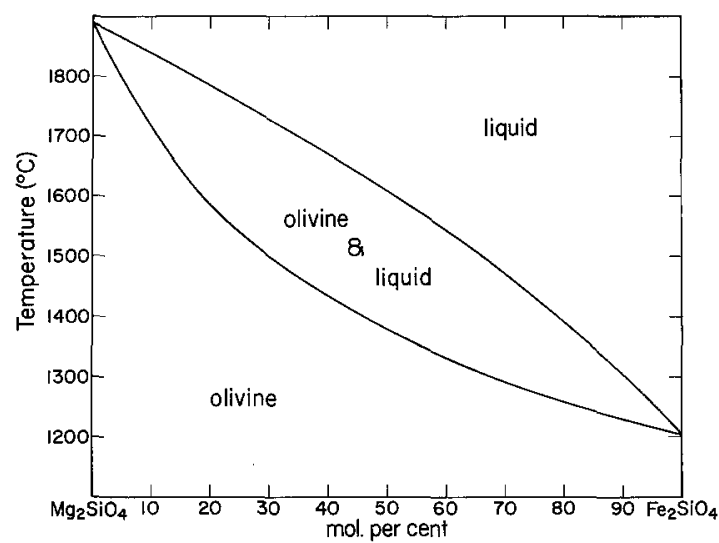

Fig. 1. The forsterite $\left(\mathrm{Mg}_{2} \mathrm{SiO}_{4}\right)$ - fayalite $\left(\mathrm{Fe}_{2} \mathrm{SiO}_{4}\right)$ solidus-liquidus loop at 1 atmosphere pressure determined by Bowen and Schairer (1935)

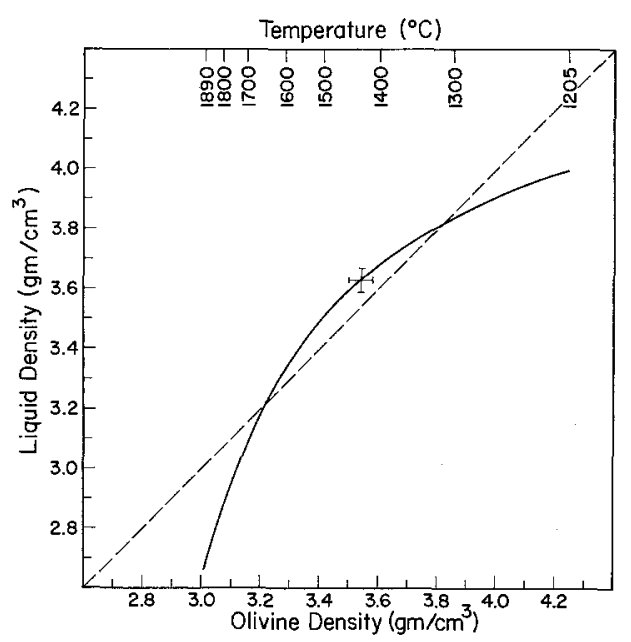

Fig. 2. Densities of olivine and coexisting liquid along the loop of Fig. 1. Error bars at $1,425^{\circ} \mathrm{C}$ are $+1 \%$. Note the region above the broken line where the density of liquid is greater than that of coexisting olivine crystals

about 1 to 4 . Most of the olivine is contained in the uppermost cumulate layer, and is about $60 \%$ by volume; the remaining $40 \%$ is intercumulus liquid. Note also that the meniscus is occupied by this cumulate crystal mush.

Another experiment was made on the same bulk composition, but at $1,500^{\circ} \mathrm{C}$ and 20 kilobars and for only $1.5 \mathrm{~h}$ in duration. The composition was placed in a graphite capsule which in turn was placed into a platinum sheath. The sample was dried in a partial vacuum and the platinum welded in order to keep the composition water-free. Pressure was imposed on the sample by means of a pistoncylinder solid media machine. The results are shown in Fig. $4 \mathrm{a}$ and $\mathrm{b}$. In this experiment the cumulus olivine crystals had largely settled to the bottom of the container and the coexisting liquid dispersed both as an intercumulus phase as well as a segregated layer of $100 \%$ liquid at the top of the capsule. Even with a bulk olivine to liquid ratio of about 44 to 56 determined by point counting, the extent of the phase separation was strong during the time period of only $1.5 \mathrm{~h}$. Figure $4 \mathrm{~b}$ shows the nature of the cumulate texture approximately half way up the cumulate pile. Although this would be described as a mesocumulate (Wager and Brown 1968), adcumulus features with good triple junc- 


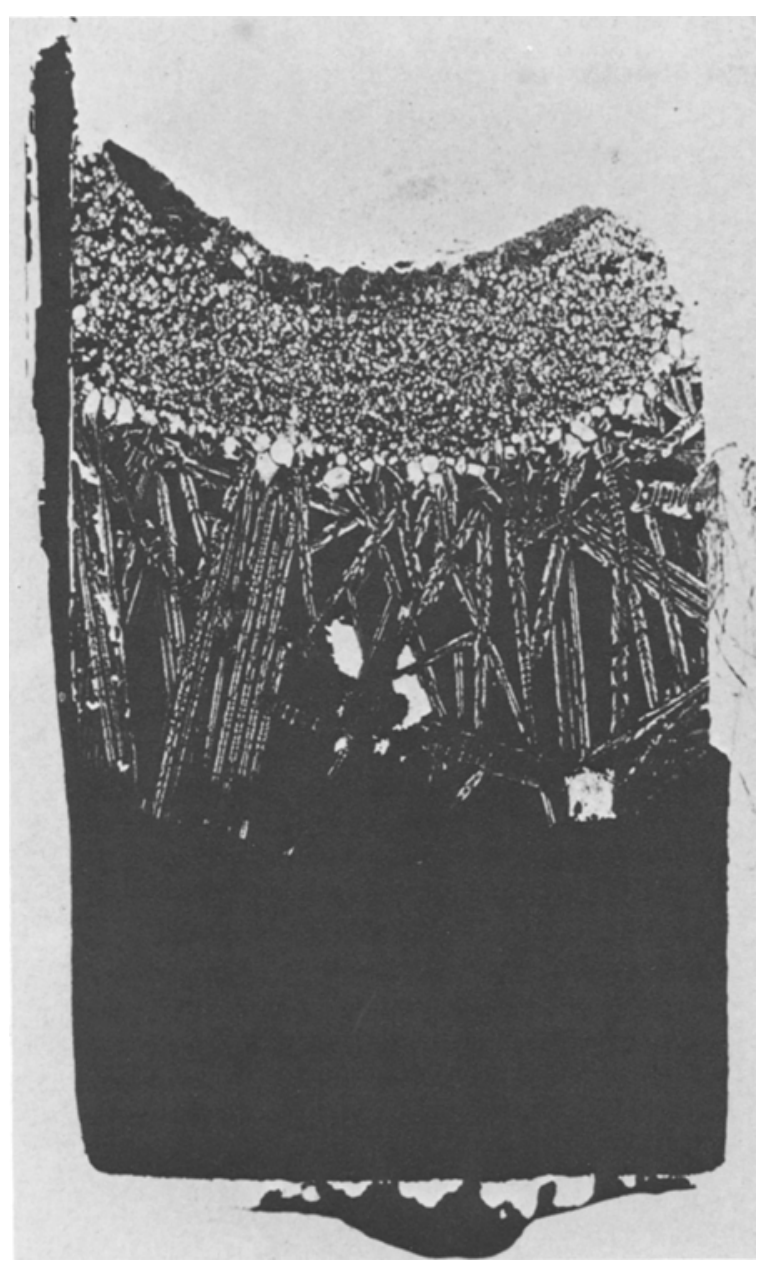

Fig. 3. Photomicrograph of an experimental result on the bulk composition $\mathrm{Fo}_{30}$ run at $1,425^{\circ} \mathrm{C}$ for $2.5 \mathrm{~h}$ in an argon atmosphere. The calculated olivine and liquid densities are shown by the error bars in Fig. 2. Note the pervasive concentration of liquidus olivine crystals at the top of the charge. Parts of the iron container wall at the right as well as some of the meniscus were lost during thin section preparation. The white patches near the center are bits of the thin section which were plucked. The interface between the cumulus olivine layer and quench liquid contains large olivine crystals as well as some round gas bubbles which appear entrained. Inner diameter of charge $=4 \mathrm{~mm}$

tion grain boundaries are beginning to develop. Most grain boundaries appear to be wetted with a melt phase as indicated by the distribution of Fe metal particles and visible grain boundaries in Fig. 4b. However, clusters of olivine crystals with adcumulate textures seem to have grain boundaries which are free of a melt phase. The base of the charge (Fig. $4 \mathrm{a}$ ) is entirely adcumulate, the complementary liquid fraction having been transposed to the top of the charge. Note also the adcumulates along the left hand side of the capsule. This is due to a temperature gradient in the charge which either affects a marginal density contrast between olivine and liquid via differential thermal expansion or imparts some convective movement to the crystal mush. If the latter explanation is correct, the sense of circulation would have been counterclockwise since the right hand side appears to have been at a higher temperature. The overall distribution of the solid and liquid phases appear to be somewhat similar to those of the "filling box' effect described by Turner and Gustafson (1981) on crystallization-convection experiments in carbonate solutions. Electron microprobe determinations of 16 randomly selected olivine grains shows them to be a very homogeneous forsterite $49.8 \pm 0.6$, fayalite $50.2 \pm 0.5$. Consequently, any temperature variations along the loop of Fig. 1 could not have been very large.

The very high liquid densities shown in Fig. 2 are in part the result of low concentrations of $\mathrm{Si}$ and $\mathrm{O}$ compared to those normally found in natural basaltic magmas, and the absence of other elements like $\mathrm{Ca}, \mathrm{Na}$, and $\mathrm{K}$ which tend to lower the intrinsic density of the liquid. Additionally, liquids at 1 atmosphere pressure can be more dense than coexisting olivine because of the extreme partitioning of the heavy element Fe into the liquid phase. This partitioning is usually expressed:

$$
K_{\mathrm{D}}=\frac{X_{\mathrm{ol}}^{\mathrm{FeO}} X_{1}^{\mathrm{MgO}}}{X^{\mathrm{FeO}} X_{\mathrm{ol}}^{\mathrm{MgO}}}
$$

and takes the value of $0.30-0.33$ for many terrestrial basalts (Roeder and Emslie 1970). However, over the temperature and composition range experimentally investigated by Bowen and Schairer (1935) in Fig. $1, K_{\mathrm{D}}$ is only about 0.22 . Together with other experimental observations, this demonstrates the profound effect that $\mathrm{SiO}_{2}$ content of a magma can have on $K_{\mathrm{D}}$ (Longhi et al. 1978; lower values of $K_{\mathrm{D}}$ corresponds to increased partitioning of $\mathrm{Fe}$ into the liquid phase). Additions of basalt-like concentrations of $\mathrm{SiO}_{2}$ to the join forsterite-fayalite results in the usual case of olivine settling at 1 atmosphere because it not only lowers the intrinsic density of the liquid but it also reduces the amount of $\mathrm{Fe}$ that becomes encorporated in the melt.

The imposition of pressure on the $\mathrm{Fe}-\mathrm{Mg}$ exchange equilibrium between olivine and silicate liquid reduces the extent to which Fe partitions into the melt by favoring the smaller $\mathrm{Mg}$ cation. Our tentative interpretation is that $K_{\mathrm{D}}$ is increased sufficiently within 20 kilobars that an olivine-liquid density inversion is established. Although we have not quantified these 20 kilobar density relations rigorously, we expect that olivine is only marginally more dense than its coexisting liquid at these pressures based on the effect of pressure on $K_{\mathrm{D}}$ (Longhi et al. 1978) and the distribution of adcumulates along the left hand side of the charge in Fig. $4 \mathrm{~b}$ as well as the bottom. However, the reader is cautioned about a possible ambiguity concerning these 20 kilobar results. Although the use of a graphite container eliminates the problem of $\mathrm{Fe}$ loss from the composition, it may have introduced some $\mathrm{CO}_{2}$ into the liquid phase. If correct, the exact nature of the density inversion is rendered ambiguous.

The high rate at which phase separation and segregation are established in these experiments is due largely to the low viscosity of the liquids. Viscosity calculations based on the method of Bottinga and Weill (1972) yield about 2 poises, which is only slightly larger than that of paraffin oil at room temperature. This compares with 4.6 poises for komatiite P9-118 of Arndt et al. (1977), 15 poises for picrite NT-23 of Elthon (1979), and 55 poises for average FAMOUS glass composition reported by Elthon (1979); these calculations apply to $1,400^{\circ} \mathrm{C}$. Comparable examples of rapid melt segregation have been reported in melting experiments on garnet-lherzolite and komatiite compositions (Arndt 1977; Green et al. 1975). 

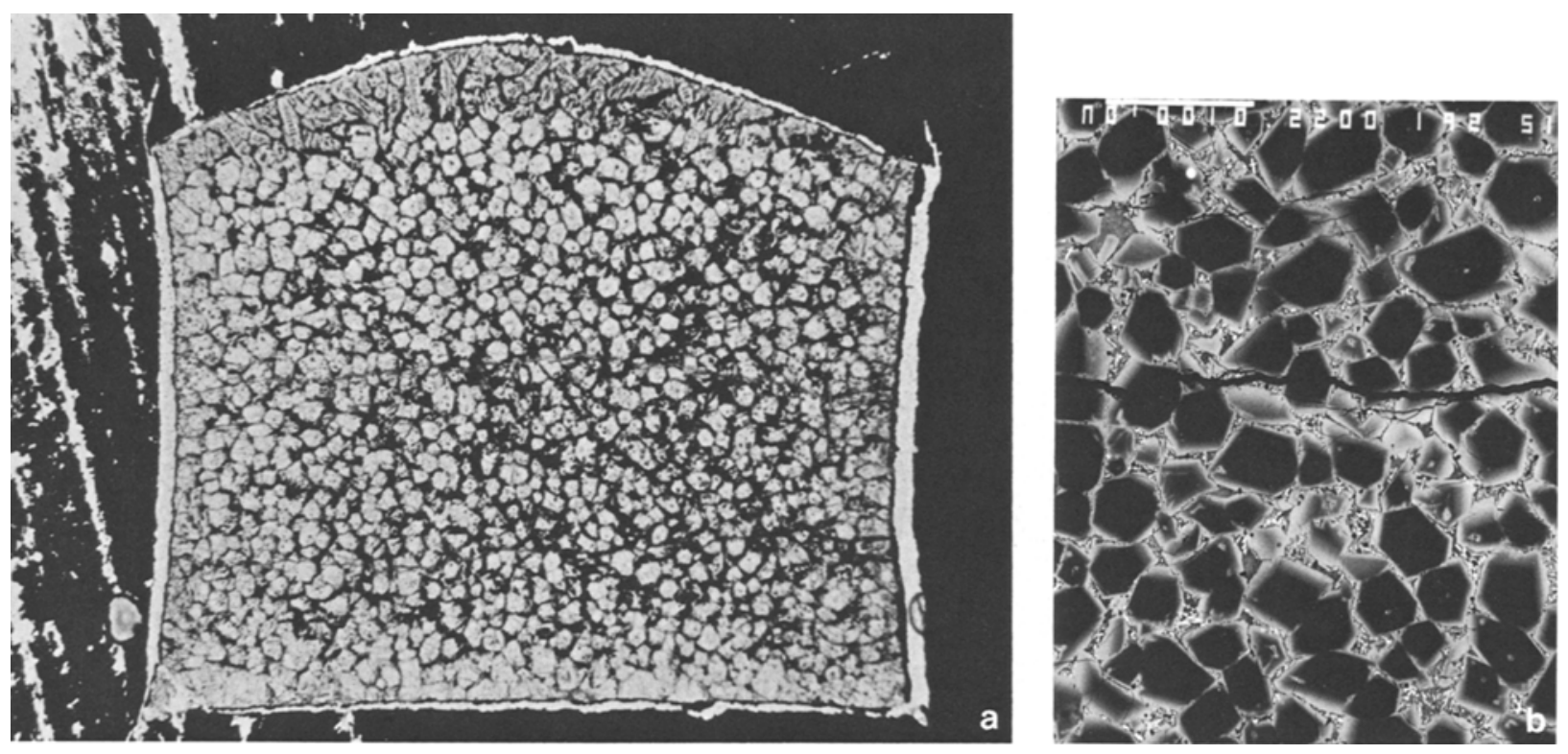

Fig. 4. a Experiment run on the bulk composition $\mathrm{Fo}_{30}$ at $1,500^{\circ} \mathrm{C}, 20$ kilobars for $1.5 \mathrm{~h}$. The segregated liquid layer at the roof of the charge is represented by quench olivine. Adcumulate textures are most strongly developed at the base and the left hand side of the charge. Width of capsule is $1.5 \mathrm{~mm}$. b Back scatter SEM image of adcumulate and mesocumulate textures near the middle of the charge. Reflective intercumulus specks are metallic $\mathrm{Fe}$

\section{Discussion}

There are many examples of igneous intrusions which apparently failed to differentiate by phase separation in a gravity field. However, there is also no paucity of examples where gravity-induced phase separation was an important geological process. The extent to which it operates as opposed to other mechanisms of differentiation can depend strongly on the composition of the magmas involved, the products of which are manifest in different geological scales of observation. Whereas tholeiitic to granitic magmas in the continental crust commonly display characteristics of in situ crystallization as envisaged by McBirney and Noyes (1979) for the Skaergaard intrusion, less silicic magmas such as partial melts in the mantle and ultramafic magmas in differentiating planets can give rise to strong phase separation even when the amount of liquid is small. Experimental results in the system forsterite-fayalite demonstrate this in part by showing rapid flotation and settling of olivine at 1 atmosphere and 20 kilobars respectively within a time duration of several hours. This gives rise to rapid segregation of a melt phase and the development of complementary adcumulates. Although this simple binary differs chemically from natural systems in the mantle, it appears to be a good analogue for exploring the mechanics of fluid flow in porous media of mantle-like silicate systems (eg., Spera 1980).

Acknowledgements. This research was done with the support of NASA grant NAGW-177 to the senior author, and the Lunar and Planetary Institute. Oscar Mullins at the Johnson Space Center is thanked for his technical guidance. This paper is Lunar and Planetary Institute Contribution No. 491.

\section{References}

Arndt NT (1977) Ultrabasic magmas and high-degree melting of the mantle. Contrib Mineral Petrol 64:205-221

Arndt NT, Naldrett AJ, Pyke DR (1977) Komatiitic and iron-rich tholeiitic lavas of Munro Township, Northeast Ontario. J Petrol 18:319-369

Bottinga Y, Weill DF (1970) Densities of liquid silicate systems calculated from partial molar volumes of oxide components. Am J Sci 269:169-182

Bottinga Y, Weill DF (1972) The viscosity of magmatic silicate liquids: A model for calculation. Am J Sci 272:438-475

Bottinga Y, Weill DF, Richet P (1982) Density calculations for silicate liquids. I. Revised methods for aluminosilicate compositions. Geochim Cosmochim Acta (in press)

Bowen NL (1919) Crystallization-differentiation in igneous magmas. J Geol 27:393-430

Bowen NL, Schairer JF (1935) The system, $\mathrm{MgO}-\mathrm{FeO}-\mathrm{SiO}_{2}$. Am J Sci 29:151-217

Campbell II, Roeder PL, Dixon JM (1978) Plagioclase buoyancy in basaltic liquids as determined with a centrifuge furnace. Contrib Mineral Petrol 67:369-377

Daly RA (1914) Igneous Rocks and Their Origin. McGraw-Hill, New York

Elthon D (1979) High magnesia liquids as the parental magma for ocean floor basalts. Nature 278:514-518

Fisher GW, Medaris LD Jr (1969) Cell dimensions and x-ray determinative curve for synthetic $\mathrm{Mg}-\mathrm{Fe}$ olivines. Am Mineral 54:741-753

Green DH, Nicholls IA, Viljoen M, Viljoen R (1975) Experimental demonstration of the existence of peridotitic liquids in earliest Archean magmatism. Geology $3: 11-14$

Hall AL (1932) The Bushveld igneous complex of the Central Transvaal. South Africa Geol Surv Mem 28

Hazen RM (1976) Effects of temperature and pressure on the crystal structure of forsterite. Am Mineral 61:1280-1293

Herzberg CT, Baker MB (1980) The cordierite- to spinel-cataclasite transition: Structure of the lunar crust. In Proceedings of the Conference on the Lunar Highlands Crust: Geochim Cosmochim Acta Suppl 12. Pergamon, New York, pp 113-132

Huppert HE, Sparks RSJ (1980) The fluid dynamics of a basaltic magma chamber replenished by influx of hot, dense ultrabasic magma. Contrib Mineral Petro1 75:279-289

Irvine TN (1980) Magmatic infiltration metasonatism, double-diffusive fractional crystallization, and adcumulus growth in the Muskox intrusion and other layered intrusions. In: Hargraves 
RB (ed) Physics of magmatic processes. Princeton University Press. Princeton, pp 325-383

Jackson ED (1961) Primary textures and mineral associations in the ultramafic zone of the Stillwater Complex, Montana. Prof Paper US Geol Surv 358

Longhi J, Walker D, Hays JF (1978) The distribution of $\mathrm{Fe}$ and $\mathrm{Mg}$ between olivine and lunar basaltic lquids. Geochim. Cosmochim Acta 42:1545-1558

Longhi J, Boudreau AE (1979) Complex igneous processes and the formation of the primitive lunar crustal rocks. Proc Lunar Planet Sci Conf 10th:2085-2106

McBirney AR, Noyes RM (1979) Crystallization and layering in the Skaergaard Intrusion. J Petrol 20:487-554

McCallum IS, Raedeke LD, Mathez EA (1980) Investigations of the Stillwater Complex: Part I. Stratigraphy and structure of the banded zone. Am J Sci 280-A:59-87

Nelson SA, Carmichael ISA (1979) Partial molar volumes of oxide components in silicate liquids. Contrib Mineral Petrol $71: 117-124$

O'Hara MJ (1968) The bearing of phase equilibria studies in synthetic and natural systems on the origin and evolution of basic and ultrabasic rocks. Earth Sci Rev 4:69-133

Rice A (1981) Convective fractionation: A mechanism to provide cryptic zoning (macrosegregation), layering, crescumulates, banded tuffs and explosive volcanism in igneous processes. J Geophys Res 86:405-417
Roeder PL, Emslie RF (1970) Olivine-liquid equilibrium. Contrib Mineral Petrol 29:275-289

Safronov VS (1978) The heating of the earth during its formation. Icarus $33: 1-12$

Spera FJ (1980) Aspects of magma transport. In Physics of magmatic processes (ed. Hargraves RB) Princeton University Press. Princeton:265-323

Stolper E, Walker D (1980) Melt density and the average composition of basalt. Contrib Mineral Petrol 74:7-12

Stolper E, Walker D, Hagar BH, Hays JF (1981) Melt segregation from partially molten source regions: The importance of melt density and source region size. J Geophys Res 86:6261-6271

Smyth JR (1975) High temperature crystal chemistry of fayalite. Am Mineral 60: 1092-1097

Turner JS (1980) A fluid-dynamical model of differentiation and layering in magma chambers. Nature 285:213-215

Turner JS, Gustafson LB (1981) Fluid motions and compositional gradients produced by crystallization or melting at vertical boundaries. J Volcanol Geotherm Res 11:93-125

Wager LR, Brown GM (1968) Layered Igneous Rocks. Oliver and Boyd, Edinburgh

Wood JA, Dickey JS, Jr, Marvin UB, Powell BN (1970) Lunar anorthosites and a geophysical model of the moon. Proc Apollo 11 Lunar Sci Conf, pp 965-988

Accepted August 9, 1982 